\title{
Economía versus epidemiologia: uma análise do trade-off entre mercados e vidas em tempos de COVID-19
}

\section{Ahmed Sameer El Khatib}

Departamento de Ciências Contábeis do Centro Universitário Álvares Penteado (FECAP)

O objetivo do presente trabalho é avaliar como o surto de novo coronavírus levou à contaminação das principais indústrias da economia global e como a resposta política e fiscal rápida de vários governos desencadeou e prolongou a recessão enquanto tentava salvar as vidas dos cidadãos. Investigamos também o efeito das políticas de distanciamento social no nível de atividades econômicas e nos preços dos índices de açóes. Foram coletados dados das bolsas de valores em quatro continentes: América do Norte, África, Ásia e Europa. Extraímos informaçóes do mercado de ações sobre o preço de fechamento $(\mathrm{PF})$, preço mais baixo $(\mathrm{PB})$ e preço mais alto (PMA) dos principais indicadores do mercado de açóes nos quatro continentes: o índice FTSE 500 (Reino Unido); SP 500 (EUA); Nikkei 225 (Japão); e o índice SA Top 40 (África do Sul). Nas estimativas, adotamos o logaritmo natural de cada dado de preço para reduzir a assimetria observada na distribuição dos dados de preço das açóes. Concentramos a análise no período que vai de Janeiro à Maio de 2020, quando o coronavírus começou a se espalhar para outros países e mercados internacionais. Examinamos empiricamente o impacto das políticas de distanciamento social nas atividades econômicas e nos índices do mercado de ações. As conclusôes revelam que o crescente número de dias de bloqueio, decisôes de política monetária e restrições internacionais de viagens afetaram severamente o nível de atividades econômicas e o fechamento, abertura, menor e mais alto preço das açôes dos principais índices da bolsa. Por outro lado, a restrição imposta ao movimento interno e o aumento dos gastos com políticas fiscais tiveram um impacto positivo no nível das atividades econômicas, embora o número crescente de casos confirmados de covo coronavírus não tenha afetado significativamente o nível das atividades econômicas. A discussão neste artigo contribui para a literatura sobre crise financeira (e.g., Allen \& Carletti, 2010; Mian \& Sufi, 2010; Stiglitz, 2010; Jagannathan, Kapoor \& Schaumburg, 2013), pois evidencia que fatores não financeiros e/ou não econômicos podem desencadear um colapso financeiro e econômico de maneiras sem precedentes.

Palavras-chave: COVID-19, Recessão Global, Mercados Financeiros, Políticas Governamentais Distanciamento Social.

\section{Economía versus epidemiología: un análisis del comercio entre mercados y vidas en tiempos de COVID-19}

El objetivo de este artículo es evaluar cómo el brote del nuevo coronavirus (COVID-19) ha conducido a la contaminación de las principales industrias de la economía global; asimismo, se busca analizar cómo la rápida respuesta política y fiscal de varios gobiernos desencadenó y prolongó la recesión al intentar salvar las vidas de los ciudadanos. También se investiga el efecto de las políticas de distanciamiento social en las actividades económicas y en los precios de los índices bursátiles. Se recopilaron datos de las bolsas de valores de cuatro continentes: América del Norte, África, Asia y Europa. Se tomó información del mercado de valores sobre el precio de cierre (PF), el precio más bajo (PB) y el precio más alto (PMA) de los principales indicadores del mercado de valores en los cuatro continentes: el índice FTSE 500 (Reino 
Unido), SP 500 (EE. UU.), Nikkei 225 (Japón) y el índice SA Top 40 (Sudáfrica). En las estimaciones, se adoptó el logaritmo natural de cada información de precios para reducir la asimetría observada en la distribución de datos de precios de acciones. El análisis se centró en el período de enero a mayo de 2020, época en la que el coronavirus comenzó a extenderse a otros países y mercados internacionales. Se examinó empíricamente el impacto de las políticas de distancia social en las actividades económicas y los índices bursátiles. Los hallazgos revelan que el creciente número de días de bloqueo, las decisiones de política monetaria y las restricciones a los viajes internacionales han afectado severamente al nivel de las actividades económicas, al cierre, a la apertura, y a los precios de acciones más bajos y más altos de los principales índices bursátiles. Por otro lado, la restricción impuesta al movimiento interno y el aumento del gasto en políticas fiscales tuvieron un impacto positivo en el nivel de las actividades económicas, aunque el creciente número de casos confirmados de coronavirus no afectó significativamente el nivel de las actividades económicas. La discusión en este artículo contribuye a la literatura sobre crisis financiera (por ejemplo, Allen \& Carletti, 2010; Mian \& Sufi, 2010; Stiglitz, 2010; Jagannathan, Kapoor \& Schaumburg, 2013), ya que muestra que factores no financieros y/o no económicos pueden desencadenar el colapso financiero y económico de formas sin precedentes.

Palabra clave: COVID-19, recesión global, mercados financieros, políticas gubernamentales de distanciamiento social

\section{Economy versus epidemiology: an analysis of trade-off between markets and lives in COVID-19 times}

The aim of this paper is to assess how the outbreak of the new coronavirus led to the contamination of major industries in the global economy and how the rapid political and fiscal response of several governments triggered and prolonged the recession while trying to save the lives of citizens. We also investigated the effect of social distance policies on the level of economic activities and on the prices of stock indexes. Data were collected from stock exchanges on four continents: North America, Africa, Asia and Europe. We extracted information from the stock market on the closing price (PF), lowest price (PB) and highest price (PMA) of the main stock market indicators on the four continents: the FTSE 500 index (United Kingdom); SP 500 (USA); Nikkei 225 (Japan); and the SA Top 40 index (South Africa). In the estimates, we adopted the natural logarithm of each price data to reduce the asymmetry observed in the distribution of stock price data. We concentrated the analysis in the period from January to May 2020, when the coronavirus started to spread to other countries and international markets. We empirically examine the impact of social distance policies on economic activities and stock market indices. The findings reveal that the increasing number of blocking days, monetary policy decisions and international travel restrictions have severely affected the level of economic activities and the closing, opening, lower and higher share prices of the main stock indexes. On the other hand, the restriction imposed on the domestic movement and the increase in spending on fiscal policies had a positive impact on the level of economic activities, although the growing number of confirmed cases of coronavirus virus did not significantly affect the level of economic activities. The discussion in this article contributes to the literature on financial crisis (eg, Allen \& Carletti, 2010; Mian \& Sufi, 2010; Stiglitz, 2010; Jagannathan, Kapoor \& Schaumburg, 2013), as it shows that non-financial and / or non-economic factors they can trigger financial and economic collapse in unprecedented ways.

Keywords: COVID-19, Global Recession, Financial Markets, Government Policies Social Distancing 


\section{Introduçáo}

Em 2019, houve ansiedade sobre o impacto de uma guerra comercial entre os Estados Unidos e China, as eleiçóes presidenciais dos Estados Unidos e o Brexit na economia mundial. Em função disso, o Fundo Monetário Internacional (FMI) previu um crescimento global moderado de 3,4\% no ano. No entanto, o COVID-19, a doença causada pelo SARS-CoV-2, uma nova cepa de coronavírus da espécie SARS, mudou inesperada e radicalmente todas as perspectivas. Devido ao medo e à incerteza mundial, além da avaliação racional de que os lucros das empresas provavelmente seriam menores devido ao impacto da COVID-19, os mercados de açôes globais eliminaram cerca de US\$ 6 trilhóes em riqueza em apenas uma semana, de 24 a 28 de fevereiro de 2020 (Ozili \& Arun, 2020). O índice S\&P 500 perdeu mais de US\$ 5 trilhóes em valor na mesma semana nos EUA, enquanto as dez maiores empresas do S\&P 500 sofreram uma perda combinada de mais de US\$ 1,4 trilhão (Financial Times, 2020), embora algumas delas tenham sido recuperadas na semana seguinte. Parte da perda de valor ocorreu devido à avaliação racional dos investidores de que os lucros das empresas diminuiriam devido ao impacto do coronavírus.

A Associação Internacional de Transporte Aéreo (IATA) afirmou que o setor de viagens aéreas perderia US\$ 113 bilhóes se o surto de COVID-19 não fosse rapidamente contido. O FMI rebaixou sua projeção de crescimento para a economia global, com o surto da COVID-19 colocando em dúvida sua projeção anterior. A indústria do turismo foi afetada, pois as oportunidades de viagens para turistas chineses, que geralmente gastam bilhóes de dólares anualmente, foram severamente reduzidas. Houve um aumento no número de cancelamentos de voos, reservas em hotéis canceladas e eventos locais e internacionais cancelados na ordem de US\$ 200 bilhôes (Financial Times, 2020). O fluxo de mercadorias através das cadeias de suprimentos globais reduziu drasticamente, uma vez que a China era o maior fabricante e exportador do mundo, e o governo chinês ordenou o fechamento das principais fábricas do país. Países como Irâ, Itália e França emitiram políticas nacionais para controlar a propagação do vírus, que já havia causado várias mortes e pressionava a infraestrutura nacional de saúde pública. Tais políticas domésticas plantaram as sementes da recessão nos países desenvolvidos e houve um consenso geral entre os economistas de que a pandemia de coronavírus mergulharia o mundo em uma recessão global Dessa forma, há consenso em afirmar que a recessão global seria tão ruim quanto a crise financeira internacional de 2007/2008, seguida de uma recuperação em 2021 ou no mais tardar em 2022 (Georgieva, 2020).

A literatura sobre a origem das recessóes é vasta (e.g., Stiglitz, 2010; Mian \& Sufi, 2010; Bezemer, 2011; Bagliano \& Morana, 2012; Jagannathan, Kapoor \& Schaumburg, 2013; Gaiotti, 2013; Bentolila, Jansen, \& Jiménez, 2018). Entretanto, a causa da recessão global em 2020 foi uma novidade na história moderna. O novo coronavírus desencadeou um novo tipo de recessão diferente dos gatilhos anteriores conhecidos na literatura. Por exemplo, a crise da dívida asiática de 1997 foi causada pelo colapso do baht tailandês (moeda local) em julho de 1997, que criou pânico, causou uma crise financeira em toda a região e recessão econômica na Ásia (Radelet \& Sachs, 1998; Mian $\&$ Sufi, 2010). A crise financeira global de 2008, que se traduziu em recessão, foi causada por uma política monetária frouxa que criou uma bolha, seguida por pelo subprime nas hipotecas, estruturas regulatórias fracas e alta alavancagem no setor bancário (Allen \& Carletti, 2010). A recessão de 2010 na Grécia foi causada pelo efeito posterior da crise financeira global, fraquezas estruturais da economia grega e falta 
de flexibilidade da política monetária como membro da zona do euro (Rady, 2012; Georgieva, 2020). Já a recessão de 2016 na Nigéria, por exemplo, foi causada pela queda no preço do petróleo, déficit na balança de pagamentos, adoçáo de um regime de taxa de câmbio flutuante, aumento no preço da gasolina, atividades de vândalos em dutos e fraquezas de infraestrutura local.

Neste artigo, apresentaremos como o surto de coronavírus levou à contaminação dos principais setores da economia global e como a resposta política e fiscal rápida de vários governos desencadeou e prolongou a recessão, quando na verdade tentava salvar as vidas dos cidadãos. Investigamos também o efeito das políticas de distanciamento social no nível de atividades econômicas e nos preços dos índices de ações.

A discussão neste artigo contribui para a literatura sobre crise financeira (e.g., Allen \& Carletti, 2010; Mian \& Sufi, 2010; Stiglitz, 2010; Jagannathan et al., 2013), pois evidencia que fatores não financeiros e/ ou não econômicos podem desencadear um colapso financeiro e econômico de maneiras sem precedentes. A implicação para a estabilidade financeira é a de que futuros testes de resistência à resiliência do mercados internacionais devem levar em consideração os fatores de saúde humana (fatores epidemiológicos) como um elemento importante em seus exercícios de teste de resistência.

\section{COVID-19: Uma pandemia, múltiplas consequências}

Dados em tempo real sobre a disseminaçáo do coronavírus (ou doença da COVID-19) foram coletados da Johns Hopkins University e revelam que os EUA tinham o maior número de indivíduos infectados, seguidos pela China, Itália e Irã em 11 de maio de 2020. As estatísticas são mostradas na tabela 1 a seguir:

Tabela 1. Estatísticas da COVID-19 em 11 de maio de 2020

\begin{tabular}{|l|c|c|c|}
\hline \multicolumn{1}{|c|}{ Países } & $\begin{array}{c}\text { Casos } \\
\text { Confirmados } \\
\text { (Total) }\end{array}$ & $\begin{array}{c}\text { Mortes } \\
\text { Confirmadas } \\
\text { (Total) }\end{array}$ & $\begin{array}{c}\text { Recuperados } \\
\text { (Total) }\end{array}$ \\
\hline Mundo & 4.153 .871 & 284.628 & 1.432 .847 \\
\hline Estados Unidos & 1.340 .643 & 79.935 & 216.169 \\
\hline Espanha & 224.350 & 26.621 & 136.166 \\
\hline Reino Unido & 224.328 & 32.140 & 1.007 \\
\hline Russia & 221.344 & 2.009 & 39.801 \\
\hline Itália & 219.814 & 30.739 & 106.587 \\
\hline França & 177.547 & 26.646 & 56.835 \\
\hline Alemanha & 172.285 & 7.611 & 145.600 \\
\hline Brasil & 163.510 & 11.207 & 64.957 \\
\hline Turquia & 139.771 & 3.841 & 95.780 \\
\hline Irã & 109.286 & 6.685 & 87.422 \\
\hline China & 84.010 & 4.637 & 79.171 \\
\hline Canadá & 70.987 & 5.101 & 32.663 \\
\hline India & 70.768 & 2.294 & 22.579 \\
\hline Peru & 67.307 & 1.889 & 21.349 \\
\hline Bélgica & 53.449 & 8.707 & 13.697 \\
\hline Holanda & 42.987 & 5.475 & 149 \\
\hline Arábia Saudita & 41.014 & 255 & 12.737 \\
\hline & Fon & & \\
\hline
\end{tabular}

Fonte: Johns Hopkins University (2020).

\subsection{Contaminação da Indústria Global}

Inicialmente, a percepçáo era de que a pandemia da COVID-19 seria localizada apenas na China. Mais tarde, espalhou-se pelo mundo através do movimento de pessoas. A dor econômica tornou-se intensa à medida que as pessoas foram convidadas a ficar em casa, e a severidade foi sentida em vários setores da economia, com proibiçóes de viagens que afetavam a indústria da aviação, cancelamentos de eventos esportivos que afetavam a indústria do esporte, a proibição de reunióes de massa que afetavam os eventos e indústrias de entretenimento (Horowitz, 2020; Elliot, 2020). 
Existem paralelos entre a crise COVID-19 e os eventos de 2007-2008: como em 2020, muitas pessoas na recessão anterior assumiram que os impactos seriam amplamente localizados (nesse caso, com base na suposição de que a crise do subprime das hipotecas seria uma problema relativamente menor que afetaria apenas os Estados Unidos, mas que afetou o sistema financeiro global) (Elliot, 2020). A súbita interrupção econômica causada pelo COVID-19 não é apenas destrutiva, mas também tem implicaçôes e múltiplas consquências indiretas, pois criou choques de demanda e oferta em quase todas as áreas do empreendimento humano (EL-Erian, 2020; Ozili \& Arun, 2020).

\subsection{Contaminação da Indústria do Turismo}

O surto de coronavírus levou os governos de muitos países a impor restriçốes às viagens não essenciais aos países afetados pelo COVID-19, suspendendo indefinidamente viagens de turismo, vistos de trabalho e vistos para imigrantes. Alguns países proibiram completamente todas as formas de viagem para dentro ou para fora de suas fronteiras, fechando todos os aeroportos do país. No auge da pandemia do coronavírus, a maioria dos avióes voava praticamente vazia devido a cancelamentos em massa de passageiros. As restriçôes de viagem impostas pelos governos subsequentemente levaram à reduçáo na demanda por todas as formas de viagem, o que obrigou algumas companhias aéreas a suspender temporariamente operaçóes como Air Baltic, LOT Polish Airlines, La Compagnie e Scandinavian Airlines. Tais restrições de viagens custaram à indústria do turismo uma perda de mais de US\$ 200 bilhóes em todo o mundo, excluindo outras perdas de receita para viagens turísticas, e estavam previstas para custar à indústria da aviação uma perda total de US\$ 113 bilhóes (IATA Economics , 2020). O Global Business Travel Association (GTBA) informou que o setor de viagens de negócios perderia US\$ 820 bilhóes em receita devido à pandemia de coronavírus nos primeiros meses de 2020.

\subsection{Contaminaçáo da Indústria de Restaurantes}

Os negócios de restaurantes foram afetados durante a pandemia, principalmente por meio da restrição de movimento anunciada pelo governo e política de distanciamento social, imposta pelo governo em muitos países. Isso levou a rápidos desligamentos nas cidades e estados para controlar a disseminação do coronavírus, que causou choque repentino em muitos restaurantes e hotéis em todo o país. Hotéis em todo o mundo testemunharam cancelamentos de reservas no valor de bilhóes de dólares, e a indústria hoteleira buscou um resgate de US\$ 150 bilhóes (Horowitz, 2020; Elliot, 2020). Os executivos de restaurantes demitiram funcionários enquanto fechavam seus negócios temporariamente. Alguns executivos de restaurantes criticaram o governo por impor a política de ficar em casa e de distanciamento social, que destruiu muitos pequenos restaurantes e bares de pequenas cidades. Eles argumentaram que o anúncio dos governos de políticas de permanência em casa ou políticas de distanciamento social foi uma maneira indireta de dizer às pessoas para não irem a bares, hotéis e restaurantes, que era uma maneira de destruir silenciosamente a indústria da hospitalidade durante a pandemia. Diversos hotéis nos Estados Unidos, Reino Unido e em alguns países europeus anunciaram a suspensão temporária de operaçóes que elevam a perda estimada de empregos para 24,3 milhóes em todo o mundo e 3,9 milhóes somente nos Estados Unidos devido ao declínio na ocupação de hotéis durante o período de pandemia. O impacto econômico da pandemia no setor hoteleiro foi mais severo do que as recessóes de 11 de setembro e 2008 combinadas (EL-Erian, 2020; Ozili \& Arun, 2020)

\subsection{Contaminação da Indústria Esportiva}

A indústria do esporte foi severamente afetada durante o surto de coronavírus. No segmento de futebol, as principais ligas europeias de futebol na Inglaterra e na 
Escócia anunciaram a suspensão imediata dos jogos de futebol por 6 semanas até 30 de abril. A superliga turca foi a última grande liga européia a suspender suas partidas. Todos os campeonatos de futebol (estaduais, Copa do Brasil e Campeonato Brasileiro) foram interrompidos. Na Fórmula 1, o Grande Prêmio de Mônaco foi cancelado. Os Jogos Olímpicos e Paraolímpicos de Verấo de Tóquio também foram adiados. No segmento de hóquei, os jogos de hóquei de 2020 na Inglaterra foram adiados. Os jogos da FIH Pro League da Inglaterra, agendados para os dias 2 a 3 e 16 a 17 de maio, foram adiados. Nos jogos de rugby, a final Pro14 prevista para 20 de junho no Cardiff City Stadium foi cancelada. $\mathrm{O}$ rugby da liga principal (MLR) foi cancelado pelo restante da temporada 2020. No segmento de beisebol, todos os principais jogos da temporada da liga de beisebol foram cancelados no México e em Porto Rico. O jogo Motorsport em Portugal foi adiado depois que o governo português declarou estado de emergência e suspendeu todos os eventos esportivos do país. No segmento de sinuca, o campeonato mundial de sinuca, que será realizado em Sheffield, de 18 de abril a 4 de maio, foi adiado. No segmento de natação, o Campeonato Europeu de Esportes Aquáticos de 2020, marcado para os dias 11 a 24 na Hungria, foi adiado para agosto. No segmento de golfe, o tour da Ladies Professional Golf Association (LPGA) foi remarcado para 10 e 13 de setembro de 2020. A perda resultante de receita para os patrocinadores e organizadores dos jogos cancelados chegou a bilhóes de dólares.

\subsection{Pandemia nos Mercados dependentes do Petróleo}

\subsubsection{A guerra de preços do petróleo}

No início de 2020, o preço do petróleo caiu devido à guerra de preços do petróleo entre a Rússia e a Arábia Saudita. A pandemia de coronavírus agravou a situação com a redução da demanda por petróleo. As restriçóes de viagens impostas durante a pandemia, que levaram a uma redução no movimento de pessoas e bens, resultaram em uma queda na demanda por combustível de aviação, carvão e outros produtos energéticos, o que posteriormente levou a uma queda no preço do petróleo devido à baixa demanda. A crise do coronavírus também afetou uma ampla gama de mercados de energia, como os mercados de carvão, gás e energia renovável, mas seu impacto nos mercados de petróleo foi mais grave porque interrompeu o movimento de pessoas e bens, o que levou a um drástico declínio na demanda para combustíveis de transporte. Quando a Arábia Saudita mais tarde forneceu excesso de petróleo ao mundo, o mercado foi inundado com muito petróleo, excedendo a demanda durante a pandemia de COVID-19 e, posteriormente, levando a uma queda no preço do petróleo que chegou a valores negativos em abril de 2020 (BBC, 2020).

\subsubsection{Perda de receita de petróleo para paises dependentes de petróleo}

O efeito da pandemia nos países dependentes de petróleo foi severo. O declínio global do preço do petróleo, combinado com a baixa demanda por derivados de petróleo no mercado internacional, levou a um déficit significativo na receita de petróleo para países dependentes de petróleo, o que aumentou os déficits em conta corrente e piorou a posição da balança de pagamentos de muitos países dependentes de petróleo como Venezuela, Angola e Nigéria. Esses países também enfrentaram pressão crescente sobre suas reservas cambiais, o que posteriormente levou à desvalorização das moedas locais em relação ao dólar. Países como Quênia, Nigéria e África do Sul sofreram uma redução no preço da gasolina nos postos de gasolina locais. Os orçamentos nacionais também foram afetados. O declínio sustentado do preço global do petróleo devido à pandemia da COVID-19 significou que o orçamento nacional atual ficou desatualizado para a maioria dos países dependentes de petróleo e precisou

Contabilidad y Negocios (15) 30, 2020 / ISSN 1992-1896 
ser revisado porque não refletia a realidade econômica atual, uma vez que o orçamento era cotado a um preço do petróleo mais alto a partir de 2019. Consequentemente, o orçamento nacional de alguns países dependentes de petróleo teve déficits maciços, o que forçou alguns países a: (i) buscar empréstimos estrangeiros do FMI, do Banco Mundial e de outros credores para financiar seus déficits orçamentários, ou ( ii) criar um novo orçamento que foi precificado usando o atual preço baixo do petróleo no mercado global.

\subsection{Contaminação de países dependentes de importação}

Muitos países dependentes de importação foram severamente afetados durante a pandemia de coronavírus. Muitos países importaram suas mercadorias essenciais dos principais países exportadores, como China, Índia e Japão, e dependem amplamente desses países para o consumo de mercadorias essenciais. A redução de mercadorias que flui através da cadeia de suprimentos global e a dependência substancial da China para bens importados levaram à escassez de suprimentos para países dependentes de importação, pois a China fechou muitas de suas fábricas de exportação. Isso levou a aumentos no preço do estoque remanescente de suprimentos importados já em países dependentes de importação, o que também desencadeou pressóes inflacionárias no preço de commodities básicas, apesar da baixa demanda geral por importaçóes devido à pandemia de coronavírus. Foi difícil encontrar importaçóes alternativas após o fechamento da China, porque muitos países fecharam parcial ou totalmente suas fronteiras, o que sufocou o comércio internacional na época.

\subsection{Contaminação do setor financeiro: Bancos e Fintechs}

A desaceleração macroeconômica levou a um aumento de 250 pontos base nos empréstimos não produtivos no setor bancário. Os bancos do setor privado tiveram a maior exposição ao risco de crédito durante o surto. Os empréstimos inadimplentes surgiram de empréstimos concedidos a pequenas e médias empresas (PMEs), companhias aéreas, hotéis, operadores turísticos, restaurantes, varejo, construção e negócios imobiliários. Durante a pandemia, houve um declínio geral no volume de transaçóes bancárias, um declínio nos pagamentos com cartão e uma queda no uso de caixas eletrônicos em todo o mundo. Isso levou a menos taxas cobradas pelos bancos que afetaram negativamente o lucro dos bancos. Os negócios das Fintechs também foram afetados. Algumas empresas de Fintech testemunharam um patrocínio muito baixo por parte dos consumidores, levando à perda de receita e lucros, o que afetou negativamente o investimento de capital dos investidores de capital de risco que financiaram empresas Fintech existentes e novas. Isso fez muitos capitalistas de risco começarem a acumular novas açóes, o que levou ao esgotamento do financiamento para alguns negócios dsa Fintechs. Por outro lado, os bloqueios devido ao surto de coronavírus resultaram em maior demanda por alguns tipos de serviços on-line, como compras on-line.

\subsection{Contaminaçáo dos mercados financeiros}

O resultado mais visível da crise da COVID-19 nos mercados financeiros foi o efeito no mercado de açôes global. Os mercados de açóes globais perderam US\$ 6 trilhôes em valor ao longo de seis dias, de 23 a 28 de fevereiro, segundo os índices da S\&P Dow Jones. Entre 20 de fevereiro e 19 de março, o índice S\&P 500 caiu 28\% (de 3.373 para 2.409), o índice FTSE 250 caiu $41,3 \%$ (de 21.866 para 12.830 ) e o Nikkei caiu $29 \%$ (de 23.479 para 16.552). No mesmo período, os grandes bancos internacionais testemunharam uma queda no preço das açóes, por exemplo, o preço das ações do Citigroup caiu 49\% (de US\$ 78,22 para 
US\$ 39,64), o preço das ações do JP Morgan Chase caiu $38 \%$ (de US\$137,49 para US\$ 85,30) e o preço das açôes do Barclays caíram 52\% (de £ 181,32 para $£$ 86,45). Embora a guerra de preços do petróleo, na qual a Rússia e a Arábia Saudita estivessem reduzindo o preço do petróleo ao aumentar a produção de petróleo, tenha desempenhado um papel importante na queda nos índices das bolsas, a queda subsequente nos índices das bolsas de março ocorreu principalmente devido à fuga dos investidores em busca de mais segurança durante a pandemia de coronavírus.

\subsection{Contaminaçáo da Indústria de Eventos}

Antes de 2020, o setor de eventos contribuía significativamente para a economia. Em 2018, por exemplo, eventos de negócios receberam mais de 1,5 bilhão de participantes em mais de 180 países (IATA Economics, 2020). O setor de eventos gerou mais de US\$ 1,07 trilhão em gastos diretos, representando gastos para planejar eventos de negócios, produzir eventos de negócios, viagens relacionadas a eventos de negócios e gastos diretos de expositores. A indústria também criou 10,3 milhóes de empregos diretos em todo o mundo e gerou US\$ 621,4 bilhões em PIB direto.

Durante o surto de coronavírus, a indústria de eventos foi afetada financeiramente por um grande número de cancelamentos - exposiçóes, shows de música ao vivo, conferências, casamentos, festas, eventos corporativos, lançamentos de marcas, feiras e muito mais. Vários grandes eventos foram cancelados, por exemplo, os eventos tecnológicos E3 e SXSW foram cancelados, o que levou a perdas diretas além de US\$ 1 bilhão. Informa atrasou ou cancelou eventos no valor de $£ 400$ milhóes devido a pandemia de coronavírus. A Gala de 2020 foi adiada indefinidamente. Nos EUA, muitas grandes empresas de gerenciamento de eventos que foram atingidas financeiramente pelo surto de coronavírus apelaram por ajuda federal do governo dos EUA. O segmento de bilhética de eventos da indústria também foi afetado. Um dos maiores eventos e ingressos globais

A empresa Eventbrite anunciou que o surto de COVID19 afetou materialmente suas perspectivas de negócios para 2020. O efeito do cancelamento crescente na Eventbrite foi táo grave que a empresa teve que retirar sua perspectiva positiva publicada anteriormente para o primeiro trimestre de 2020. O efeito do surto nos eventos ao vivo globais foi agravado pela política de distanciamento social imposta por vários governos.

\subsection{Contaminaçáo da Indústria do Entretenimento}

A indústria cinematográfica global sofreu uma perda de US\$ 5 bilhóes durante o surto de coronavírus. Várias produçôes cinematográficas de Hollywood foram adiadas indefinidamente, o que significava adeus ao teatro e cinema. A Aliança Internacional de Empregados em Teatros Teatrais (IATSE) informou que cerca de 120.000 empregos abaixo da linha de entretenimento foram perdidos devido à pandemia de coronavírus, a maioria dos quais eram empregados de teatros. $\mathrm{O}$ encerramento da pandemia resultou na perda de 120.000 empregos mantidos por seus 150.000 membros, e o IATSE advogou que a indústria do entretenimento deveria ser incluída no pacote planejado de estímulo (ou resgate) federal. Na Itália, o surto de COVID-19 afetou severamente a indústria do entretenimento, que sofreu perdas estimadas em milhóes de euros por semana: de 23 de fevereiro a $1^{\circ}$ de março de 2020 . Havia perdas estimadas de 7,3 milhóes de euros no setor de exibição de filmes, 7,2 milhóes de euros no segmento de teatro, 4,1 milhôes de euros no segmento de música ao vivo, 2,5 milhóes de euros no segmento de atividades de dança e 1,8 milhão de euros no segmento de exposiçóes. No Reino Unido, estima-se que 50.000 freelancers do setor perderiam seus empregos como resultado da 
pandemia da COVID-19, de acordo com a BECTU (União de Radiodifusão, Entretenimento, Comunicaçôes e Teatro). Coletivamente, os níveis de desemprego na indústria do entretenimento aumentaram para níveis sem precedentes, e ainda havia dúvidas sobre se a indústria do entretenimento receberia parte do pacote federal de estímulo planejado, já que muitos legisladores argumentaram que a indústria do entretenimento não era o principal motor da economia, e alguns argumentaram que a indústria do entretenimento não contribui muito para as atividades econômicas em comparação com os setores financeiro e de manufatura.

\subsection{Contaminaçáo da Indústria da Saúde}

Em muitos países, os serviços de hospitais públicos cresceram em alta demanda, mas a maioria dos equipamentos de teste estava em hospitais privados. A China fechou temporariamente todos os hospitais na cidade central de Wuhan, o epicentro de um surto de coronavírus. Os hospitais do Irã lutaram para lidar com o surto de coronavírus. Na Espanha, o governo espanhol nacionalizou todos os hospitais privados e prestadores de serviços de saúde, pois o vírus estava se espalhando muito rapidamente. Cingapura tinha instalaçóes e trabalhadores de saúde suficientes para lidar com o crescente número de pacientes com COVID-19, e hospitais privados estavam convidando e aceitando pacientes estrangeiros com COVID-19. O Ministério da Saúde (MS) em Cingapura aconselhou subseqüentemente todos os médicos em hospitais públicos e privados e clínicas especializadas, a parar imediatamente de aceitar novos pacientes estrangeiros que não moram em Cingapura.

O surto de coronavírus também afetou a cadeia de suprimentos farmacêuticos. Fabricantes de drogas em todo o mundo confiaram muito nos ingredientes fabricados nas fábricas chinesas. Cerca de $60 \%$ dos ingredientes farmacêuticos ativos (API) do mundo foram fabricados na China antes do surto de coronavírus, e o surto de coronavírus causou sérios problemas de suprimento quando a China encerrou a maioria de suas fábricas, incluindo fábricas que produzem drogas. Muitas empresas farmacêuticas não armazenaram quantidades substanciais de APIs antes do surto de coronavírus e, como resultado, alguns medicamentos essenciais foram escassos. As empresas farmacêuticas que haviam armazenado uma quantidade substancial de APIs em seu armazém se recusaram a vendê-las por medo de ficar sem suprimentos, enquanto outras estavam dispostas a vender apenas a um preço muito alto. A dependência excessiva dos fabricantes chineses de APIs representava o maior risco para a indústria farmacêutica global e o surto de COVID-19 ampliou ainda mais o risco.

As seguradoras de saúde também foram afetadas. Muitas seguradoras de saúde nos EUA não conseguiram lidar com os pagamentos do seguro a hospitais e as seguradoras procuraram ser incluídas no pacote de incentivo federal planejado, pois a perspectiva econômica do setor de saúde era negativa. O índice S\&P 500 de assistência médica gerenciada caiu para $7 \%$ em fevereiro, indicando que os investidores achavam que o setor de saúde seria severamente atingido. A agência de classificação de risco da Moody's rebaixou a perspectiva do setor de saúde pública e sem fins lucrativos, de estável para negativa, devido à propagação contínua da doença por coronavírus (COVID-19). Moody relatou que o setor de saúde provavelmente apresentaria menos fluxo de caixa em 2020 em comparaçáo com 2019 e queda de receita devido ao cancelamento de cirurgias eletivas. A agência de classificação também afirmou que, mesmo que o surto de coronavírus pudesse ser contido, as empresas de assistência médica sem fins lucrativos já estavam enfrentando despesas crescentes e incerteza generalizada. Além disso, banqueiros de investimento que investiram fortemente. 


\section{Políticas governamentais dos países}

\subsection{Resposta política geral}

As medidas políticas imediatas (adotadas em poucos dias) adotadas pelos formuladores de políticas de todo o mundo para lidar com a recessão global induzida por coronavírus podem ser divididas em quatro categorias: (i) medidas monetárias, (ii) medidas fiscais, (iii) medidas de saúde pública e (iv) medidas de controle de pessoas.

Tabela 2. Políticas governamentais imediatas durante a recessão global de 2020

\begin{tabular}{|c|c|c|c|}
\hline \# & Tipo & Políticas governamentais & Países \\
\hline \multirow[t]{5}{*}{1} & \multirow{5}{*}{$\begin{array}{l}\text { Medidas } \\
\text { de Política } \\
\text { Monetária }\end{array}$} & $\begin{array}{l}\text { Tolerância regulatória aos bancos e do principal e juros } \\
\text { dos devedores afetados pelo Covid-19 }\end{array}$ & Irlanda, China, Nigéria e Itália \\
\hline & & $\begin{array}{l}\text { Provisão de liquidez pelos bancos centraios para o mer- } \\
\text { cado financeiro e de títulos }\end{array}$ & China e Estados Unidos \\
\hline & & $\begin{array}{l}\text { Compra de títulos e valores mobiliários pelos bancos } \\
\text { centrais }\end{array}$ & Austrália, Estados Unidos e Canadá \\
\hline & & Redução da taxa de juros pelos bancos centrais & $\begin{array}{l}\text { Turquia, Estados Unidos, Nova Zelândia, Japão, Reino } \\
\text { Unido, Nigéria, Coréia do Sul, Brasil e Canadá }\end{array}$ \\
\hline & & $\begin{array}{l}\text { Garantia de fluxo de caixa para bancos, pequenas e } \\
\text { médias empresas, setor da saúde pública e indivíduos }\end{array}$ & Austrália, Nigéria, Estados Unidos e Reino Unido \\
\hline \multirow[t]{3}{*}{2} & \multirow[t]{3}{*}{$\begin{array}{l}\text { Medidas } \\
\text { Fiscais }\end{array}$} & $\begin{array}{l}\text { Grande aporte de estímulo federal para setores e indús- } \\
\text { trias mais afetados pela Pandemia }\end{array}$ & Reino Unido, Estados Unidos, Austrália e Nigéria \\
\hline & & Ajuda financeira aos cidadãos (distribuição de renda) & Austrália, Estados Unidos, Reino Unido e Índia \\
\hline & & Pagamento de assistência social familiar & Austrália e Estados Unidos \\
\hline \multirow[t]{4}{*}{3} & \multirow{4}{*}{$\begin{array}{l}\text { Medidas } \\
\text { de Saúde } \\
\text { Pública }\end{array}$} & Quarentena Pública & $\begin{array}{l}\text { Índia, Brasil, Estados Unidos, Reino Unido e a maioria } \\
\text { dos países }\end{array}$ \\
\hline & & Quarentena de Fronteira & $\begin{array}{l}\text { Polônia, Vietnã, Índia, Reino Unido, Estados Unidos, } \\
\text { Paquistấo, Austrália e Colômbia }\end{array}$ \\
\hline & & Açóes de conscientização para ficar em casa & Itália, Irã, Nigéria e Reino Unido \\
\hline & & Política de distanciamento social & $\begin{array}{l}\text { África do Sul, Brasil, Emirados Árabes Unidos, Estados } \\
\text { Unidos, Reino Unido, Alemanha, China, Paquistão, } \\
\text { Austrália e Israel }\end{array}$ \\
\hline \multirow[t]{5}{*}{4} & \multirow{5}{*}{$\begin{array}{l}\text { Medidas de } \\
\text { Controle de } \\
\text { Pessoas }\end{array}$} & Liberação temporária de detentos dos sistemas prisionais & Irã e Estados Unidos \\
\hline & & Fechamento de escolas e universidades & Reino Unido, Espanha, Itália, África do Sul e Brasil \\
\hline & & $\begin{array}{l}\text { Uso das forças armadas para impor o confinamento em } \\
\text { casa }\end{array}$ & Malásia, Itália, Israel, África do Sul e Espanha \\
\hline & & Proibição de viagens nacionais e internacionais & $\begin{array}{l}\text { Estados Unidos, Áustria, Austrália, Bolívia, Canadá, } \\
\text { China, Colômbia, Egito, Alemanha, Grécia e Haiti }\end{array}$ \\
\hline & & Suspensão de novos vistos de entradas no país & $\begin{array}{l}\text { África do Sul, Canadá, Singapura, China, Nigéria, } \\
\text { Ghana e Brasil }\end{array}$ \\
\hline
\end{tabular}

Fonte: Goldman Sachs Global Investment Research (2020). 


\subsection{Resposta política em alguns países em desenvolvimento}

Algumas respostas políticas (e medidas imediatas) tomadas por algunns países em desenvolvimento da Europa Central e Oriental, Oriente Médio e África em 24 de março de 2020 são mostradas na tabela 3 a seguir:

Tabela 3. Políticas governamentais na Europa, Oriente Médio e África

\begin{tabular}{|c|c|c|c|c|c|c|}
\hline Países & 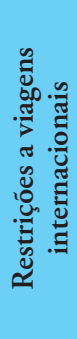 & 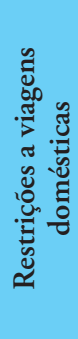 & 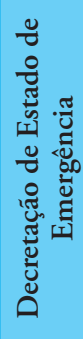 & 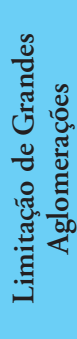 & 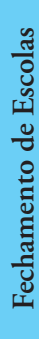 & 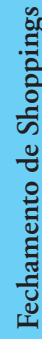 \\
\hline República Tcheca & $\mathrm{x}$ & & $\mathrm{X}$ & $\mathrm{X}$ & $\mathrm{X}$ & $\mathrm{X}$ \\
\hline Hungria & $\mathrm{X}$ & & $\mathrm{X}$ & $\mathrm{X}$ & $\mathrm{X}$ & \\
\hline Polônia & $\mathrm{X}$ & & $\mathrm{X}$ & $\mathrm{X}$ & $\mathrm{X}$ & $\mathrm{X}$ \\
\hline Romênia & $\mathrm{X}$ & & $\mathrm{X}$ & $\mathrm{X}$ & $\mathrm{X}$ & $\mathrm{X}$ \\
\hline Rússia & $\mathrm{X}$ & & & $\mathrm{X}$ & $\mathrm{X}$ & \\
\hline Ucrânia & $\mathrm{X}$ & $\mathrm{x}$ & & $\mathrm{X}$ & $\mathrm{X}$ & $\mathrm{x}$ \\
\hline Egito & $\mathrm{x}$ & & & $\mathrm{X}$ & $\mathrm{x}$ & \\
\hline Israel & $\mathrm{X}$ & $\mathrm{X}$ & & $\mathrm{X}$ & $\mathrm{X}$ & $\mathrm{X}$ \\
\hline Líbano & $\mathrm{X}$ & $\mathrm{X}$ & & $\mathrm{X}$ & $\mathrm{X}$ & $\mathrm{X}$ \\
\hline Arábia Saudita & $\mathrm{X}$ & $\mathrm{X}$ & & $\mathrm{X}$ & $\mathrm{X}$ & $\mathrm{X}$ \\
\hline Turquia & $\mathrm{X}$ & $\mathrm{X}$ & & $\mathrm{x}$ & $\mathrm{X}$ & $\mathrm{X}$ \\
\hline Ghana & $\mathrm{X}$ & & & $\mathrm{x}$ & $\mathrm{X}$ & $\mathrm{X}$ \\
\hline Quênia & $\mathrm{X}$ & & & $\mathrm{x}$ & $\mathrm{X}$ & $\mathrm{X}$ \\
\hline Nigéria & $\mathrm{X}$ & & & $\mathrm{X}$ & $\mathrm{X}$ & \\
\hline África do Sul & $\mathrm{X}$ & & & $\mathrm{X}$ & $\mathrm{X}$ & \\
\hline Índia & $\mathrm{x}$ & $\mathrm{x}$ & & $\mathrm{x}$ & $\mathrm{x}$ & $\mathrm{x}$ \\
\hline
\end{tabular}

Fonte: Goldman Sachs Global Investment Research (2020).

\subsection{Medidas de política fiscal}

Também foram anunciadas medidas de política fiscal em muitos países para mitigar o impacto econômico negativo da COVID-19, conforme elencado na tabela 4 a seguir:

Tabela 4. Políticas fiscais governamentais para combater os efeitos do Coronavírus

\begin{tabular}{|l|c|c|}
\hline \multicolumn{1}{|c|}{ Países } & $\begin{array}{c}\text { Aumento Total de Gastos } \\
\text { (em moeda local) }\end{array}$ & \% do PIB \\
\hline Estados Unidos & USD \$ 484 bilhóes & 2,4 \\
\hline Reino Unido & GBP 350 bilhões & 11,8 \\
\hline Canadá & C\$ 107 bilhôes & 6,2 \\
\hline República Tcheca & CZK 100 bilhões & 1,8 \\
\hline Polônia & ZL 212 bilhóes & 9,2 \\
\hline Romênia & RON 9 bilhões & 0,9 \\
\hline Rússia & RUB 1,4 trilhões & 0,3 \\
\hline Egito & EGP 50 bilhões & 0,8 \\
\hline Israel & ILS 2,8 bilhões & 0,4 \\
\hline Arábia Saudita & SR 120 bilhões & 3,9 \\
\hline Turquia & LIRA 100 bilhóes & 18,5 \\
\hline Nigéria & NGN 3,5 trilhões & 2,3 \\
\hline Índia & ₹1,7 bilhões & 9,6 \\
\hline
\end{tabular}

Fonte: Banking Services (2020).

\subsection{Medidas de política monetária}

Medidas monetárias expansivas foram adotadas por muitos bancos centrais para estimular a economia por meio de ajustes na taxa de juros, conforme mostrado nas tabelas 5 e 6 .

As medidas de suprimento de recursos financeiros (monetários) também foram adotadas por muitos bancos centrais por meio de programas de compra de títulos ou como fundos diretos de alívio de coronavírus. A tabela 6 abaixo mostra o total de gastos do banco central por alguns bancos centrais para estimular a economia. 
Tabela 5. Políticas monetárias adotadas na Europa, Oriente Médio e África

\begin{tabular}{|c|c|c|c|c|}
\hline \multirow[b]{2}{*}{ Países } & \multicolumn{3}{|c|}{ Taxa de Juros (\%) } & \multirow{2}{*}{$\begin{array}{c}\text { Novas } \\
\text { compras } \\
\text { de Ativos }\end{array}$} \\
\hline & $\begin{array}{c}\text { Em } 1^{\circ} \text { de } \\
\text { janeiro } \\
\text { de } 2020\end{array}$ & $\begin{array}{l}\text { Maio } \\
\text { de } \\
2020\end{array}$ & $\begin{array}{c}\text { Projeçáo para } \\
\text { o } 2^{\circ} \text { trimestre } \\
\text { de } 2020\end{array}$ & \\
\hline $\begin{array}{l}\text { República } \\
\text { Tcheca }\end{array}$ & 2,00 & 1,75 & 1,00 & $\begin{array}{c}\text { Títulos } \\
\text { Públicos }\end{array}$ \\
\hline Hungria & 0,90 & 0,90 & 0,90 & - \\
\hline Polônia & 1,50 & 1,00 & 0,50 & $\begin{array}{c}\text { Títulos } \\
\text { Públicos }\end{array}$ \\
\hline Romênia & 2,50 & 2,00 & 1,50 & $\begin{array}{c}\text { Títulos } \\
\text { Públicos }\end{array}$ \\
\hline Rússia & 6,25 & 6,00 & 6,00 & $\begin{array}{l}\text { Títulos } \\
\text { Interna- } \\
\text { cionais }\end{array}$ \\
\hline Ucrânia & 13,50 & 10,00 & 8,50 & $\begin{array}{l}\text { Títulos } \\
\text { Interna- } \\
\text { cionais }\end{array}$ \\
\hline Egito & 12,25 & 9,25 & 9,25 & $\begin{array}{l}\text { Títulos } \\
\text { Públicos }\end{array}$ \\
\hline Israel & 0,25 & 0,25 & 0,10 & $\begin{array}{c}\text { Títulos } \\
\text { Públicos }\end{array}$ \\
\hline $\begin{array}{l}\text { Arábia } \\
\text { Saudita }\end{array}$ & 2,25 & 1,00 & 1,00 & $\begin{array}{c}\text { Títulos } \\
\text { Públicos }\end{array}$ \\
\hline Turquia & 12,00 & 9,75 & 9,75 & - \\
\hline Ghana & 16,00 & 14,50 & 14,50 & - \\
\hline Quênia & 8,50 & 7,25 & 7,00 & - \\
\hline Nigéria & 13,50 & 13,50 & 13,50 & - \\
\hline África do Sul & 6,50 & 5,25 & 4,75 & - \\
\hline Índia & 5,15 & 4,40 & 4,00 & - \\
\hline
\end{tabular}

Fonte: Goldman Sachs Global Investment Research (2020).

\section{Tabela 6. Gastos dos Bancos Centrais}

\begin{tabular}{|l|l|}
\hline \multicolumn{1}{|c|}{ Bancos Centrais } & \multicolumn{1}{c|}{ Valores } \\
\hline Reserve Bank of India & US\$ 50 bilhões \\
\hline Central Bank of Russia & US\$ 4 bilhões \\
\hline Bank of Canada & US\$ 703 milhões \\
\hline European Central Bank & US\$ 796,2 bilhões \\
\hline Bank of England & US\$ 248 bilhões \\
\hline
\end{tabular}

\begin{tabular}{|c|c|}
\hline Bancos Centrais & Valores \\
\hline Federal Reserve & US \$ 3 trilhōes \\
\hline People Bank of China & US\$ 79 bilhões \\
\hline Bank of France & US $\$ 48,9$ bilhôes \\
\hline Central Bank of Italy & US $\$ 27,2$ bilhôes \\
\hline Reserve Bank of Australia & US\$ 56 bilhóes \\
\hline Banco Central do Brasil & US\$ 231 bilhões \\
\hline Total & US\$ 4.54 trilhões \\
\hline
\end{tabular}

Fonte: Banking Services (2020).

\section{Trade-Off entre vidas e economias}

\section{Uma decisão difícil}

Os formuladores de políticas do governo e dos bancos centrais foram confrontados com duas decisóes importantes: "salvar as pessoas antes de salvar a economia" ou "salvar a economia antes de salvar as pessoas". Uma escolha teve que ser feita porque era difícil conseguir as duas ao mesmo tempo. De certa forma, não se pode salvar as pessoas e a economia ao mesmo tempo, porque para salvar as pessoas (que também são agentes econômicos) durante o surto, deve-se pedir que elas fiquem em casa para controlar a propagação do coronavírus, o que significa que as atividades econômicas terão que parar ou reduzir significativamente suas rotinas, o que provocará uma desaceleração econômica. Em muitos países, os formuladores de políticas consideraram que era melhor salvar as pessoas antes de salvar a economia e, como resultado, foi permitido que a economia sofresse drasticamente em alguns países por alguns meses.

\subsection{Resposta política contraditória e conflitante}

Durante a pandemia de coronavírus, muitas das respostas rápidas às políticas foram insuficientes, embora as políticas tenham sido formuladas com boas intençôes. A política monetária, por exemplo, ajudou a 
acalmar os mercados financeiros, mas não parou a recessão. Os bancos centrais responderam ao surto de coronavírus alterando variáveis de política monetária, como diminuir as taxas de juros e aumentar a oferta de dinheiro (ou crédito) para setores cruciais da economia. Mas a política monetária sozinha não poderia induzir a demanda quando houvesse uma fuga geral para a segurança entre consumidores e investidores - poucas pessoas estavam comprando alguma coisa ou fazendo novos investimentos. Ficou claro para muitos economistas que a política monetária não é uma vacina, não pode curar uma recessão. As políticas monetárias expansionistas adotadas em muitos países durante o surto incentivaram atividades econômicas, mas os agentes econômicos não conseguiram se envolver em atividades econômicas porque os governos impuseram restriçōes de distanciamento social por medo de entrar em contato com o coronavírus durante o surto. Os bancos centrais estavam "esperando" resultados particulares e queriam mudar a agulha nessa direção ao máximo que podiam, mas, na realidade, seus melhores esforços não alcançariam resultados tão efetivos.

\subsection{Utilizar despesas fiscais amplas e prioridade do setor}

Alguns países usaram um amplo pacote de estímulo fiscal federal (ou resgate) para mitigar o efeito da COVID-19 na economia durante o surto. A determinaçáo de quais setores receberáo parte do pacote de estímulo e quais setores não receberão o pacote de estímulo se tornou uma questáo política em alguns países como o Reino Unido e os EUA, pois provocou debates sobre se o governo considerava o setor de entretenimento, o setor de hospitalidade e os economia circular seja menos importante e insignificante para a economia e inelegível para receber algum financiamento do pacote federal de estímulo em comparação com o setor bancário, manufatura, educação, farmacêutico e os setores da aviaçáo, que foram considerados contribuintes significativos para a economia. Alguns membros de setores excluídos protestaram porque achavam que o governo náo considerava outros setores como contribuintes significativos para a economia.

\subsection{A política rápida destruiu muito rapidamente um segmento da indústria da hospitalidade}

Políticas como a 'política de permanência em casa' e a 'política de distanciamento social' ou "política de isolamento social" danificaram gravemente a renda de restaurantes, bares, lojas e hotéis em muitos locais, em alguns casos resultando no fechamento. Destruiu muitas empresas no setor de hospitalidade de maneiras que não eram previstas, e o governo falhou em assumir a responsabilidade pelo fracasso de pequenas e grandes empresas que não sobreviveram ao surto de coronavírus devido à política de distanciamento social imposta pelo governo e restriçóes de bloqueio. Ou a política de distanciamento social foi implementada muito cedo ou a política foi levada ao extremo por cidadãos e viajantes que tinham medo de patrocinar essas empresas por medo de contrair a doença COVID-19.

\section{Análise empírica: Impacto das políticas de distanciamento social}

\subsection{Dados e metodologia}

Nesta seção, examinamos empiricamente se as políticas de distanciamento social afetaram as atividades econômicas. Os dados coletados são de um mês, de 23 de março a 11 de maio de 2020 . O período restrito da amostra permite capturar o impacto direto (e imediato) das políticas de distanciamento social no desempenho do mercado de açóes e no nível geral de economia/atividades comerciais no auge da crise do coronavírus em março e abril de 2020. 
Coletamos dados das principais bolsas de valores em quatro continentes: América do Norte, África, Ásia e Europa. Extraímos informaçôes do mercado de açóes sobre o preço de fechamento $(\mathrm{PF})$, preço mais baixo (PB) e preço mais alto (PMA) dos principais indicadores do mercado de açóes nos quatro continentes: o índice FTSE 500 (Reino Unido), SP 500 (EUA), o Nikkei 225 (Japão) e o índice SA Top 40 (África do Sul). Nas estimativas, adotamos o logaritmo natural de cada dado de preço para reduzir a assimetria observada na distribuição dos dados de preço das ações.

Além disso, coletamos dados no Purchasing Manager's Index (PMI) do Japão, Reino Unido, EUA e África do Sul para os meses de março, abril e maio de 2020. O PMI é um índice da direção predominante das tendências econômicas nos setores de manufatura e serviços, derivado de pesquisas mensais de empresas do setor privado. O PMI é usado como proxy para o nível de atividades econômicas/comerciais gerais (NAE).

Para as variáveis explicativas, usamos três variáveis para capturar políticas de distanciamento social: número de dias de bloqueio (DBL), restrição de movimento interno (RMI) e restriçóes internacionais de viagens (RVI). Também controlamos as decisóes de política monetária (PM), o tamanho dos gastos com política fiscal (PFI) e o número de casos confirmados (CC) da COVID-19 relatados nos quatro países. Utilizamos o logaritmo natural das observaçôes variáveis de PFI e CC para reduzir a assimetria observada na distribuição de dados. Os dados para as variáveis RMI, RVI, PM, PFI e CC foram coletados no banco de dados do Oxford COVID-19 Government Response Tracker (OxCGRT). O OxCGRT é um novo banco de dados que monitora a resposta política dos governos durante o surto ocasionado pelo novo coronavírus. A variável DBL foi calibrada da seguinte maneira: no primeiro dia de bloqueio é atribuído um valor ' 1 ', no segundo dia de bloqueio é atribuído um valor ' 2 ', no quinto dia de bloqueio é atribuído um valor '5' e assim sucessivamente.

\subsection{Especificação do modelo}

Utililizamos um modelo multivariado, aplicando o método de Mínimos Quadrados Ordinários (MQO) em cada equação:

$\mathrm{NAE}_{i, t}=c+\mathrm{DB} L_{i, t}+R \mathrm{MI}_{i, t}+\mathrm{RV}_{i, t}+\mathrm{PM}_{i, t}+\mathrm{PFI}_{i, t}$ $C C_{i, t}+e_{i, t}$

$\mathrm{VMA}_{i, t}=c+\mathrm{DB} L_{i, t}+R \mathrm{MI}_{i, t}+\mathrm{RVI}_{i, t}+\mathrm{PM}_{i, t}+\mathrm{PFI}_{i, t}$ $+C C_{i, t}+e_{i, t}$

Onde:

$\mathrm{NAE}$ = nível de atividades econômicas gerais

$\mathrm{VMA}=\mathrm{o}$ vetor logarítmico das variáveis do mercado de ações: PF, $\triangle \mathrm{PF}, \mathrm{PB}$ e PMA

$\mathrm{i}=$ país

$\mathrm{t}=$ dia útil da semana

As estatísticas descritivas e a tabela de correlação são relatadas na tabela 7 e 8 a seguir:

Tabela 7. Estatísticas Descritivas

\begin{tabular}{|c|c|c|c|c|c|c|c|c|c|c|c|}
\hline & PF & PMA & PB & PA & NAE & DBL & RMI & RVI & PM & PFI & CC \\
\hline 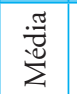 & 9,3 & 9,3 & 9,2 & 9,2 & 40,9 & 11,5 & 1,8 & 2,1 & 1,2 & 15102 & 9,6 \\
\hline 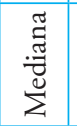 & 9,2 & 9,2 & 9,2 & 9,19 & 40,0 & 11,5 & 2,0 & 3,0 & 0,1 & 8299 & 9,2 \\
\hline 离 & 10,7 & 10,7 & 10,7 & 10,7 & 48,5 & 22,0 & 2,0 & 3,0 & 5,2 & 45580 & 13,6 \\
\hline 恋 & 7,7 & 7,7 & 7,7 & 7,7 & 32,9 & 1,0 & 1,0 & 0,0 & $-0,1$ & 0,0 & 5,6 \\
\hline 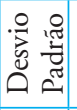 & 1,1 & 1,1 & 1,1 & 1,1 & 5,1 & 6,3 & 0,4 & 1,3 & 2,1 & 1728 & 2,2 \\
\hline 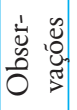 & 88 & 88 & 88 & 88 & 88 & 88 & 76 & 76 & 76 & 88 & 88 \\
\hline
\end{tabular}

Contabilidad y Negocios (15) 30, 2020 / ISSN 1992-1896 
$\mathrm{DBL}=$ número de dias de bloqueio. $\mathrm{RMI}=$ restrição ao movimento interno. $\mathrm{RVI}=$ restrições de viagens internacionais. $\mathbf{P M}=$ taxas de política monetária. $\mathrm{PF}=$ logaritmo natural dos gastos com políticas fiscais. CC = logaritmo natural do número de casos confirmados. $\mathrm{NAE}=$ nível geral de negócios / atividades econômicas. $\mathrm{PF}=$ logaritmo natural do preço de fechamento das ações para cada índice de açôes. $\mathrm{PB}=$ logaritmo natural do menor preço das ações para cada índice de açóes. PMA = logaritmo natural do preço mais alto das açóes para cada índice de açóes. PA = logaritmo natural do preço inicia (de abertura) das açóes para cada índice de açôes.

\subsection{Discussáo dos resultados}

Os resultados são apresentados na tabela 9. O coeficiente DBL é negativo e significativo nas colunas 1 , 2, 3, 4 e 5 e indica que o número de dias de bloqueio afetou significativamente os preços de fechamento, abertura, menor e mais alto do mercado de açóes e o nível das atividades econômicas gerais (NAE). O coeficiente da RMI é positivo e está significativamente

Tabela 8. Correlação de Pearson

\begin{tabular}{|c|c|c|c|c|c|c|c|c|c|c|c|}
\hline Variáveis & PF & PMA & PB & PA & NAE & DBL & RMI & RVI & PM & PFI & CC \\
\hline PF & 1,00 & & & & & & & & & & \\
\hline PMA & $\begin{array}{c}0,99^{* * *} \\
(439,97)\end{array}$ & $\begin{array}{l}1,00 \\
----\end{array}$ & & & & & & & & & \\
\hline PB & $\begin{array}{c}0,99^{* * *} \\
(427,87)\end{array}$ & $\begin{array}{c}0,99^{* * *} \\
(462,81)\end{array}$ & $\begin{array}{l}1,00 \\
-\cdots--\end{array}$ & & & & & & & & \\
\hline PA & $\begin{array}{c}0,99^{* * *} \\
(281,49)\end{array}$ & $\begin{array}{c}0,99^{* * *} \\
(414,06)\end{array}$ & $\begin{array}{c}0,99^{* * *} \\
(518,09)\end{array}$ & $\begin{array}{l}1,00 \\
-\ldots-- \\
\end{array}$ & & & & & & & \\
\hline NAE & $\begin{array}{c}0,22^{* *} \\
(1,97)\end{array}$ & $\begin{array}{l}0,22^{* *} \\
(1,99)\end{array}$ & $\begin{array}{l}0,21^{*} \\
(1,90)\end{array}$ & $\begin{array}{l}0,21^{*} \\
(1,92)\end{array}$ & $\begin{array}{l}1,00 \\
----\end{array}$ & & & & & & \\
\hline DBL & $\begin{array}{c}-0,16 \\
(-1,42) \\
\end{array}$ & $\begin{array}{c}-0,16 \\
(-1,42)\end{array}$ & $\begin{array}{c}-0,15 \\
(-1,33) \\
\end{array}$ & $\begin{array}{l}-0,15 \\
(-1,37)\end{array}$ & $\begin{array}{c}-0,72^{* * *} \\
(-9,18)\end{array}$ & $\begin{array}{l}1,00 \\
-\ldots-- \\
\end{array}$ & & & & & \\
\hline RMI & $\begin{array}{c}-0,37^{* * *} \\
(-3,46)\end{array}$ & $\begin{array}{c}-0,37^{* * *} \\
(-3,48)\end{array}$ & $\begin{array}{c}-0,37^{* * *} \\
(-3,48)\end{array}$ & $\begin{array}{c}-0,37^{* * *} \\
(-3,47)\end{array}$ & $\begin{array}{c}-0,32^{* * *} \\
(-2,97)\end{array}$ & $\begin{array}{c}0,11 \\
(0,94)\end{array}$ & $\begin{array}{l}1,00 \\
-\ldots-- \\
\end{array}$ & & & & \\
\hline RVI & $\begin{array}{l}0,23^{* *} \\
(2,12)\end{array}$ & $\begin{array}{l}0,24^{* *} \\
(2,12)\end{array}$ & $\begin{array}{l}0,23^{* *} \\
(2,10) \\
\end{array}$ & $\begin{array}{l}0,23^{* *} \\
(2,09)\end{array}$ & $\begin{array}{c}0,33^{* * *} \\
(3,03)\end{array}$ & $\begin{array}{c}-0,07 \\
(-0,61)\end{array}$ & $\begin{array}{c}-0,18 \\
(-1,62)\end{array}$ & $\begin{array}{l}1,00 \\
---- \\
\end{array}$ & & & \\
\hline PM & $\begin{array}{c}0,70^{* * *} \\
(8,53)\end{array}$ & $\begin{array}{c}0,70^{* * *} \\
(8,51)\end{array}$ & $\begin{array}{c}0,70^{* * *} \\
(8,48)\end{array}$ & $\begin{array}{c}0,70^{* * *} \\
(8,50)\end{array}$ & $\begin{array}{c}0,09 \\
(0,81) \\
\end{array}$ & $\begin{array}{c}-0,15 \\
(-1,30)\end{array}$ & $\begin{array}{c}0,32^{* * *} \\
(2,97)\end{array}$ & $\begin{array}{c}0,39^{* * *} \\
(3,65)\end{array}$ & $\begin{array}{l}1,00 \\
---- \\
\end{array}$ & & \\
\hline PFI & $\begin{array}{l}0,94^{* * *} \\
(23,70)\end{array}$ & $\begin{array}{l}0,94^{* * *} \\
(23,84)\end{array}$ & $\begin{array}{l}0,93^{* * *} \\
(23,51)\end{array}$ & $\begin{array}{l}0,93^{* * *} \\
(23,57)\end{array}$ & $\begin{array}{l}0,25^{* *} \\
(2,23)\end{array}$ & $\begin{array}{c}-0,17 \\
(-1,50)\end{array}$ & $\begin{array}{l}-0,19^{*} \\
(-1,70) \\
\end{array}$ & $\begin{array}{c}0,48^{* * *} \\
(4,73)\end{array}$ & $\begin{array}{l}0,85^{* * *} \\
(14,26)\end{array}$ & $\begin{array}{l}1,00 \\
-\ldots-- \\
\end{array}$ & \\
\hline CC & $\begin{array}{l}-0,90^{* * *} \\
(-18,07)\end{array}$ & $\begin{array}{l}-0,90^{* * *} \\
(-18,15)\end{array}$ & $\begin{array}{l}-0,89^{* * *} \\
(-17,69)\end{array}$ & $\begin{array}{l}-0,90^{* * *} \\
(-17,86)\end{array}$ & $\begin{array}{c}-0,50^{* * *} \\
(-4,96)\end{array}$ & $\begin{array}{c}0,53^{* * *} \\
(5,47)\end{array}$ & $\begin{array}{c}0,43^{* * *} \\
(4,17)\end{array}$ & $\begin{array}{c}-0,14 \\
(-1,22)\end{array}$ & $\begin{array}{c}-0,56^{* * *} \\
(-5,87)\end{array}$ & $\begin{array}{l}-0,81^{* * *} \\
(-12,04)\end{array}$ & $\begin{array}{l}1,00 \\
----\end{array}$ \\
\hline
\end{tabular}

***, ${ }^{* *},{ }^{*}$ representam significância estatística nos níveis de 1\%, 5\% e 10\%. A estatística T é relatada entre parênteses.

Fonte: Estatísticas da pesquisa. 
relacionado ao NAE e às variáveis de preço das açóes. Isso indica que a restrição imposta ao movimento interno teve um efeito positivo no nível das atividades econômicas e no fechamento, abertura, menor e maior preço das açóes. O coeficiente de IR está negativamente relacionado ao NAE e a todas as variáveis de preço das açóes nas colunas (1) a (5). Isso indica que a restriçáo de viagens internacionais imposta durante a pandemia de coronavírus teve um efeito significativo e negativo no nível das atividades econômicas e nos preços das açóes. $\mathrm{O}$ coeficiente MP está negativamente relacionado ao NAE e às variáveis de preço das açôes nas colunas (1) a (5). Isso indica que as decisóes de política monetária tiveram um efeito significativo e negativo no nível de atividades econômicas e no fechamento, abertura, preços mais baixos e mais altos das ações. O coeficiente de PFI é positivo e significativo em todas as estimativas e indica que o tamanho dos gastos com políticas fiscais teve um impacto positivo nos preços das açóes e no nível de atividades econômicas. O coeficiente de CC é negativo e insignificante, o que indica que o número de casos confirmados não teve um efeito significativo no nível de atividades econômicas.

Tabela 9. Impacto da Política de Distanciamento Social nas Bolsas de Valores e nas Atividades Comerciais

\begin{tabular}{|c|c|c|c|c|c|}
\hline & (1) & (2) & (3) & (4) & (5) \\
\hline & $\begin{array}{c}\text { Preço de Fechamento } \\
\text { (PF) }\end{array}$ & $\begin{array}{l}\text { Preço de Abertura } \\
\text { (PA) }\end{array}$ & Preço mais Baixo $(\mathrm{PB})$ & $\begin{array}{l}\text { Preço mais Alto } \\
\text { (PMA) }\end{array}$ & (NAE) \\
\hline SDL & $\begin{array}{c}-0,113^{* * *} \\
(-4,87)\end{array}$ & $\begin{array}{c}-0,112^{* * *} \\
(-4,85)\end{array}$ & $\begin{array}{c}-0,112^{* * *} \\
(-4,87)\end{array}$ & $\begin{array}{c}-0,112^{* * *} \\
(-4,91)\end{array}$ & $\begin{array}{c}-0,588^{* * *} \\
(-3,20)\end{array}$ \\
\hline RIM & $\begin{array}{l}1.369^{*} \\
(1,90)\end{array}$ & $\begin{array}{l}1.388^{*} \\
(1,95)\end{array}$ & $\begin{array}{l}1.325^{*} \\
(1,86)\end{array}$ & $\begin{array}{c}1.430^{* *} \\
(2,02)\end{array}$ & $\begin{array}{c}30.356^{* * *} \\
(5,36)\end{array}$ \\
\hline IR & $\begin{array}{c}-0,580^{* * *} \\
(-4,99)\end{array}$ & $\begin{array}{c}-0,579^{* * *} \\
(-5,05)\end{array}$ & $\begin{array}{c}-0,587^{* * *} \\
(-5,10)\end{array}$ & $\begin{array}{c}-0,571^{* * *} \\
(-4,99)\end{array}$ & $\begin{array}{c}2,706^{* * *} \\
(2,95)\end{array}$ \\
\hline MP & $\begin{array}{c}-1.107^{* * *} \\
(-6,10)\end{array}$ & $\begin{array}{c}-1.113^{* * *} \\
(-6,22)\end{array}$ & $\begin{array}{c}-1.096^{* * *} \\
(-6,12)\end{array}$ & $\begin{array}{c}-1.125^{* * *} \\
(-6,32)\end{array}$ & $\begin{array}{c}-11.517^{* * *} \\
(-8,07)\end{array}$ \\
\hline FP & $\begin{array}{c}0,0003^{* * *} \\
(40,67)\end{array}$ & $\begin{array}{c}0,0003^{* * *} \\
(41,2)\end{array}$ & $\begin{array}{c}0,0003^{* * *} \\
(41,07)\end{array}$ & $\begin{array}{c}0,0003^{* * *} \\
(41,44)\end{array}$ & $\begin{array}{c}0,001^{* * *} \\
(21,68)\end{array}$ \\
\hline $\mathrm{CC}$ & $\begin{array}{c}0,685^{* * *} \\
(4,37)\end{array}$ & $\begin{array}{c}0,680^{* * *} \\
(4,39)\end{array}$ & $\begin{array}{c}0,691^{* * *} \\
(4,45)\end{array}$ & $\begin{array}{c}0,674^{* * *} \\
(4,37)\end{array}$ & $\begin{array}{l}-1,467 \\
(-1,19)\end{array}$ \\
\hline $\mathrm{R}^{2}$ & 83,47 & 83,87 & 83,96 & 83,84 & 61,47 \\
\hline $\mathrm{R}^{2}$ Ajust. & 82,29 & 82,72 & 82,71 & 82,68 & 58,71 \\
\hline Observ. & 76 & 76 & 76 & 76 & 76 \\
\hline
\end{tabular}

$\mathrm{DBL}=$ número de dias de bloqueio. $\mathrm{RMI}=$ restriçẫo ao movimento interno. $\mathrm{RVI}=$ restriçôes de viagens internacionais. $\mathrm{PM}=$ taxas de política monetária. $\mathrm{PFI}=$ logaritmo natural dos gastos com políticas fiscais. $\mathrm{CC}=$ logaritmo natural do número de casos confirmados. NAE = nível geral de negócios $/$ atividades econômicas. $\mathrm{PF}=$ logaritmo natural do preço de fechamento das açôes para cada índice de açóes. $\mathrm{PB}=$ logaritmo natural do menor preço das açôes para cada índice de açóes. PMA = logaritmo natural do preço mais alto das açōes para cada índice de açóes. PA = logaritmo natural do preço das açōes de abertura para cada índice de açóes.

***, **, * representam significância estatística nos níveis de 1\%, 5\% e 10\%. T-estatística são relatados entre parênteses 


\subsection{Implicação dos resultados}

No geral, os resultados mostraram que o aumento do número de dias de bloqueio, decisóes de política monetária e restriçóes internacionais de viagens impostas no auge da crise do coronavírus afetaram gravemente o nível das atividades econômicas gerais e a abertura, a menor e a mais alta cotação das ações dos principais índices das bolsas de valores. Por outro lado, a restrição imposta ao movimento interno e aos gastos com políticas fiscais teve um impacto positivo no nível das atividades econômicas, enquanto o número de casos confirmados se relacionou positivamente com a abertura, os preços mais altos e mais baixos das ações dos principais índices de açóes. A implicação das constataçóes é que os gastos com políticas fiscais parecem ser mais eficazes para mitigar o efeito da pandemia de COVID-19 do que as decisôes de política monetária, particularmente porque a adoção de políticas monetárias acomodatícias por muitos bancos centrais pode agravar as pressóes inflacionárias que poderiam piorar a estabilidade macroeconômica no curto prazo.

\section{Consideraçóes finais e recomendaçóes para pesquisas futuras}

Analisamos o surto de coronavírus e a disseminação para a economia global que desencadeou a recessão global em 2020. Os formuladores de políticas em muitos países estavam sob pressão para responder ao surto no novo coronavírus. Como resultado, muitos governos tomaram decisóes políticas rápidas que tiveram efeitos positivos e negativos de longo alcance em suas respectivas economias, mas muitos países mergulharam em recessão. Políticas de distanciamento social e restriçóes de bloqueio de pessoas foram impostas em muitos países e há argumentos de que essas políticas sociais possam desencadear uma recessão como nunca vista anteriormente. Nossas descobertas na seção 5 mostraram que uma política de distanciamento social de 30 dias ou restrição de bloqueio prejudica a economia por meio de uma redução no nível de atividades econômicas gerais e por seu efeito negativo nos preços das ações.

Em muitos países, os legisladores apoiaram uma política estendida de distanciamento social, condenando as conseqüências do distanciamento social na economia. A recessão que se seguiu, que muitos países experimentaram, foi um reflexo da difícil escolha que os formuladores de políticas tiveram que fazer ao escolher salvar a economia antes de salvar as pessoas ou salvar as pessoas antes de salvar a economia; Neste Trade-Off entre epidemiologia e economia, muitos países escolheram o último. Houve críticas de que as políticas eram muito rápidas, prematuras ou insuficientes e de que as políticas se contradiziam em algumas áreas, por exemplo, a política monetária acomodatícia incentivava os agentes econômicos a se engajarem em atividades econômicas enquanto os bloqueios e o distanciamento social impedia a realização de atividades econômicas.

Pelo lado positivo, a crise de saúde pública induzida por coronavírus criou uma oportunidade para muitos governos fazerem reformas permanentes e duradouras no setor de saúde pública. Países como o Reino Unido e a Espanha consertaram seu sistema público de saúde e corrigiram outras deficiências na infraestrutura pública, como a transição para educação on-line, sistemas de transporte e sistemas de detecção de doenças em hospitais públicos. Alguns governos também usaram a crise como uma oportunidade para consertar o sistema econômico e o sistema financeiro com o pacote de estímulo federal mais planejado. 
Nosso estudo tem algumas limitaçôes. A principal limitação deste trabalho de pesquisa é o curto período de análise devido ao conjunto de dados limitado. Um período mais longo de estudo pode capturar as conseqüências socioeconômicas das políticas governamentais durante a crise do coronavírus. Além disso, à medida que eventos futuros se desenrolam, pode haver repercussóes em outros setores que não analisamos neste estudo. Estudos futuros sobre contaminaçóes econômicos podem ser estendidos para três direçóes. Primeiro, estudos futuros poderiam examinar o impacto nas políticas governamentais na economia informal, aspecto não abordado neste trabalho. Segundo, seria relevante explorar como os bancos e instituiçóes financeiras reagiram ao desenvolvimento de políticas econômicas durante a crise do coronavírus. Por fim, seria relevante adicionar mais países à amostra, uma vez que o novo coronavírus alcançou mais de 180 países, bem como estender a análise para o período pós-Pandemia de COVID-19.

\section{Referências}

Allen, F., \& Carletti, E. (2010). An Overview of the Crisis: Causes, Consequences, and Solutions. International Review of Finance, 10(1), 1-26. https://doi. org/10.1111/j.1468-2443.2009.01103.x

Bagliano, F. C., \& Morana, C. (2012). The Great Recession: US Dynamics and Spillovers to the World Economy. Journal of Banking \& Finance, 36(1), 1-13. https:// doi.org/10.1016/j.jbankfin.2011.06.002

Banking Services. (2020). Central Banks and Monetary Authorities. Bank for International Settlements. Recuperado de https://www.bis.org/ [Consulta: 10 de abril de 2020].

BBC. (2020). Coronavirus: Oil producers expected to increase crude output. $B B C$ News. Recuperado de https://www.bbc.com/news/business-53386423 [Consulta: 13 de julho de 2020].
Bentolila, S., Jansen, M., \& Jiménez, G. (2018). When Credit Dries Up: Job Losses in the Great Recession. Journal of the European Economic Association, 16(3), 650-695. https://doi.org/10.1093/jeea/jvx021

Bezemer, D. J. (2011). The Credit Crisis and Recession as a Paradigm Test. Journal of Economic Issues, 45(1), 1-18. https://doi.org/10.2753/JEI0021-3624450101

El-Erian, M. (2020, March 17). The Coming Coronavirus Recession and the Uncharted Territory Beyond. Foreign Affairs. Recuperado de https://www.foreignaffairs. com/articles/2020-03-17/coming-coronavirus-recession [Consulta: 4 de maio de 2020].

Elliot, L. (2020). Prepare for the Coronavirus Global Recession. The Guardian. Recuperado de https:// www.theguardian.com/business/2020/mar/15/prepare-for-the-coronavirus- global-recession [Consulta: 12 de maio de 2020].

Financial Times. (2020). Global Recession Already Here, Say Top Economists. Financial Times. Recuperado de https://www.ft.com/content/be732afe-6526-11eaa6cd-df28cc3c6a68 [Consulta: 28 de abril de 2020].

Gaiotti, E. (2013). Credit Availability and Investment: Lessons from the "great recession". European Economic Review, 59, 212-227. https://doi.org/10.1016/j.euroecorev.2012.12.007

Georgieva, K (2020). IMF Managing Director Kristalina Georgieva's Statement Following a G20 Ministerial Call on the Coronavirus Emergency. International Monetary Fund. Recuperado de https:/www.imf.org/en/News/Articles/2020/03/23/ pr2098-imf-managing-director-statement- followinga-g20-ministerial-call-on-the-coronavirus-emergency [Consulta:20 de março de 2020].

Giles, C. (2020, March 15). Global recession already here, say top economists. Financial Times. Recuperado de https://www.ft.com/content/be732afe-6526-11eaa6cd-df28cc3c6a68 [Consulta: 20 de março de 2020]. 
Goldman Sachs Global Investment Research. (2020). Goldman Sachs Global Investment Research and COVID-19. Recuperado de https://www.goldmansachs.com/ insights/topics/economic-outlooks.html [Consulta: 10 de abril de 2020].

Horowitz, J. (2020, March 16). The Global Coronavirus Recession is Beginning. CNN Business. Recuperado de https://edition.cnn.com/2020/03/16/economy/ global-recession-coronavirus/index.html [Consulta: 4 de abril de 2020].

IATA Economics. (2020, March 24). COVID-19 updated impact assessment. Recuperado de https:/www.iata. org/en/iata-repository/publications/economic-reports/ third-impact-assessment/ [Consulta: 4 de abril de 2020].

International Monetary Fund (IMF) Communications Department. (2020, March 23). The Great Lockdown: Worst Economic Downturn Since the Great Depression. Recuperado de https://www.imf.org/en/News/ Articles/2020/03/23/pr2098-imf-managing-directorstatement-following-a-g20-ministerial-call-on-thecoronavirus-emergency [Consulta: 11 de maio de 2020].

Jagannathan, R., Kapoor, M., \& Schaumburg, E. (2013). Causes of the Great Recession of 2007-2009: The Financial Crisis was the Symptom not the Disease. Journal of Financial Intermediation, 22(1), 4-29. https://doi.org/10.1016/j.jfi.2012.06.002

Johns Hopkins University (2020). COVID-19 United Cases by State. Recuperado de https://coronavirus.jhu.edu/ us-map [Consulta: 11 de abril de 2020].
Mian, A., \& Sufi, A. (2010). The Great Recession: Lessons from Microeconomic Data. American Economic Review, 100(2), 51-56. https://doi.org/10.1257/aer. 100.2.51

Ozili, P. (2020, January). 100 Quotes from the Global Financial Crisis: Lessons for the future. SSRN: Electronic Journal. https://doi.org/10.2139/ssrn.3500921

Ozili, P., \& Arun, T. (2020, March). Spillover of COVID-19: Impact on the Global Economy. SSRN Electronic Journal. https://doi.org/10.2139/ssrn.3562570

Radelet, S., \& Sachs, J. (1998). The Onset of the East Asian Financial Crisis (NBER Working Paper 6680). Cambridge: National Bureau of Economic Research. https://doi.org/10.3386/w6680

Rady, D. A. M. (2012, September). Greece Debt Crisis: Causes, Implications and Policy Options. Academy of Accounting and Financial Studies Journal, 16, 87-96.

Stiglitz, J. E. (2010). Interpreting the Causes of the Great Recession of 2008. In S. Cecchetti, W. Dudley, M. Shirakawa, J. Stiglitz, \& N. Wllink (Auth.), Financial System and Macroeconomic Resilience: Revisited (BIS Research Paper 53) (pp. 4-19). Basel: Bank for International Settlements

Fecha de recepción: 29 de mayo de 2020 Fecha de aceptación: 29 de setiembre de 2020 Correspondencia: ahmed.khatib@usp.br 